\title{
Vietnam: Shell Nuclei, Pearl Hatcheries, and Pearl Farming
}

Nicholas Sturman, Kwanreun Lawanwong, Nuttapol Kitdee, and Devchand Chodhry

A field trip to Vietnam in late 2019 permitted team members from GIA's Bangkok laboratory access to a shell nucleus manufacturing factory and two pearl farms managed by Orient Pearls (Bangkok) Ltd. The team was able to see how high-quality bead nuclei used on the company's own farms, among others, are produced from the raw shells shipped to Vietnam. The end product is used on both farms to produce a range of attractive Vietnamese bead cultured pearls suitable for use in fine-quality jewelry on a commercial scale. The incredible attention to detail required to produce the bead nuclei, and the subsequent application of these nuclei in the culturing process, must be seen in person to be truly appreciated. This account will help explain the shell nucleus manufacturing process, as well as the pearl farming activities witnessed on two Vietnamese pearl farms.

Vietnam is a land of great diversity and beauty. From the hustle and bustle of Ho Chi Minh City to the beauty of Ha Long Bay and Hoi An (both UNESCO World Heritage Sites), there are innumerable places of interest. Economically, Vietnam is beginning to see significant investment from a wide range of businesses, domestic and foreign. While still dependent on agriculture, the country is emerging as a major player in the electronics and oil/gas industries, among others. These factors, together with a robust tourism industry, are resulting in an expanding population with greater prosperity than ever before.

Jewelry, including pearl jewelry, ranks high on the list of luxury items, as there is a significant range of price points at which disposable wealth can be spent. From the costume jewelry sector to high-end offerings, there is something to suit all tastes. While cultured pearls, accounting for $99.9 \%$ of the market since the early 1900s, do not usually fall into the

See end of article for About the Authors and Acknowledgments.

Gems \& Gemology, Vol. 56, No. 3, pp. 402-415,

http://dx.doi.org/10.5741/GEMS.56.3.402

(C) 2020 Gemological Institute of America higher-end bracket, there remains a healthy demand from consumers (Shor, 2007; Heebner, 2015). The choice of bead cultured pearls in the marketplace is also diverse. Consumers may choose from the usual imported gray to black Tahitian bead cultured pearls, "golden" bead cultured pearls from the Philippines or Indonesia, and bead cultured pearls produced in China.

Hạ Long Bay (figures 1 and 2) in northern Vietnam is where most pearl farms, producing predominantly "akoya" (Pinctada fucata martensii) pearls, may be found. These farms are a mix of independent operations and joint ventures with the Vietnamese government. A prime example of the latter is Spica, a Vietnamese-Japanese joint venture that has produced bead cultured pearls for more than a decade. Some farming activity is also found in the waters off southern Vietnam at Nha Trang, as will be seen later, and Phu Quoc (Strack, 2006).

Vietnam has produced saltwater cultured pearls commercially since the 1990s. However, the first attempts reportedly began in the 1960s (Strack, 2006). Today, based on the $300-400 \mathrm{~kg}$ production from the two farms visited in this report, the country is estimated to produce approximately 2,000 kg per annum. The majority of the production is akoya, with a smaller quantity of Pinctada maxima, and much of the production is currently exported to China, Japan, India, and the United Sates. When the harvests are good, the quality tends to be higher, but the opposite also holds true.

\section{SHELL BEAD NUCLEI}

One of the most important aspects of the culturing process is the sourcing of suitable freshwater shell bead nuclei to insert into the host mollusks, which deposits nacre around them and ultimately produces cultured pearls (Taylor and Strack, 2008). While this may appear to be a simple matter of finding any type of shell and fashioning beads from it, the truth of the matter is more complex and demanding than most people realize. The use of saltwater bead nuclei fashioned from clamshell (Tridacna-species mollusks) has been known to result in their cracking during the 


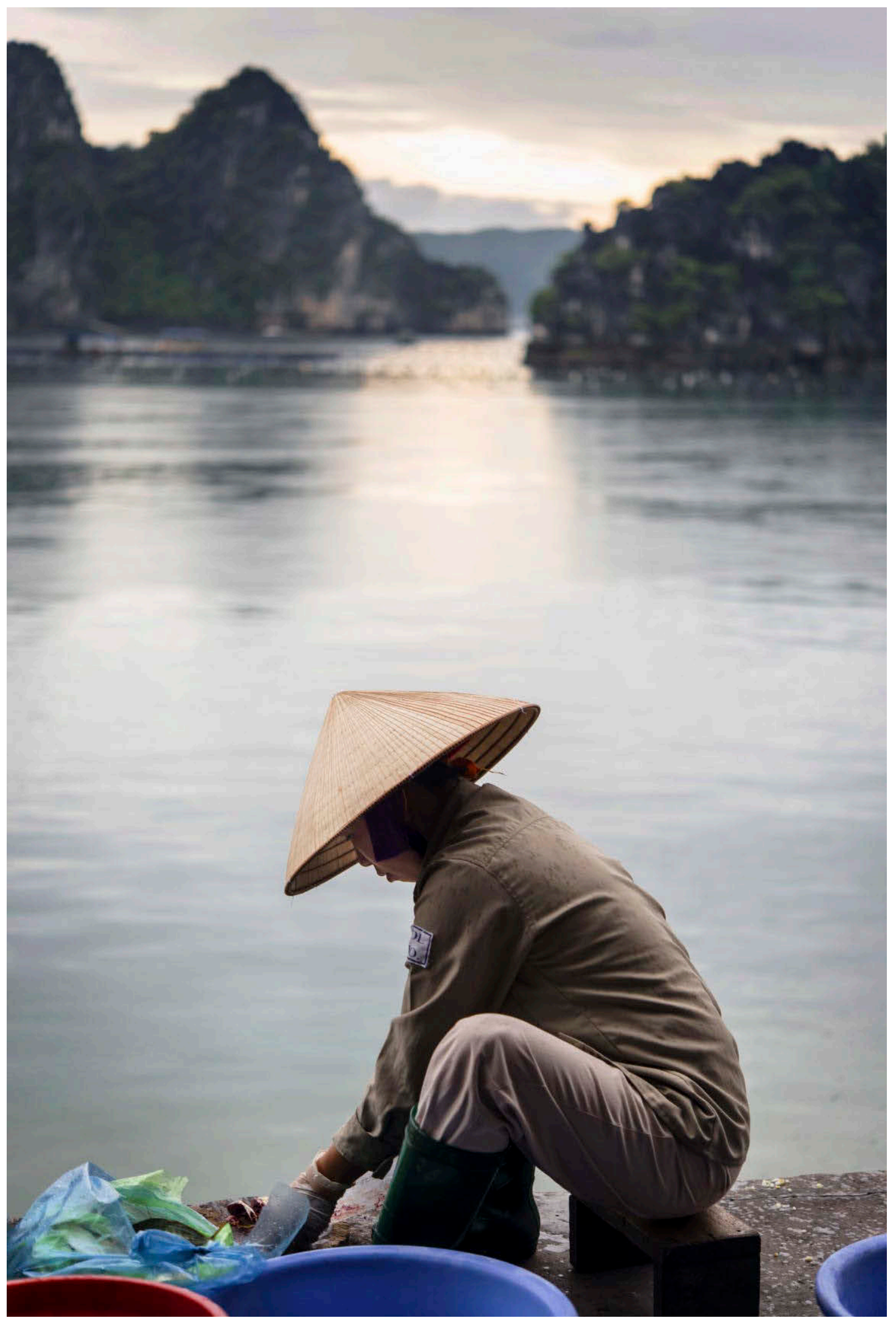

Figure 1. A Vietnamese pearl farm employee busy with his duties in Ha Long Bay. Photo by Nuttapol Kitdee. 


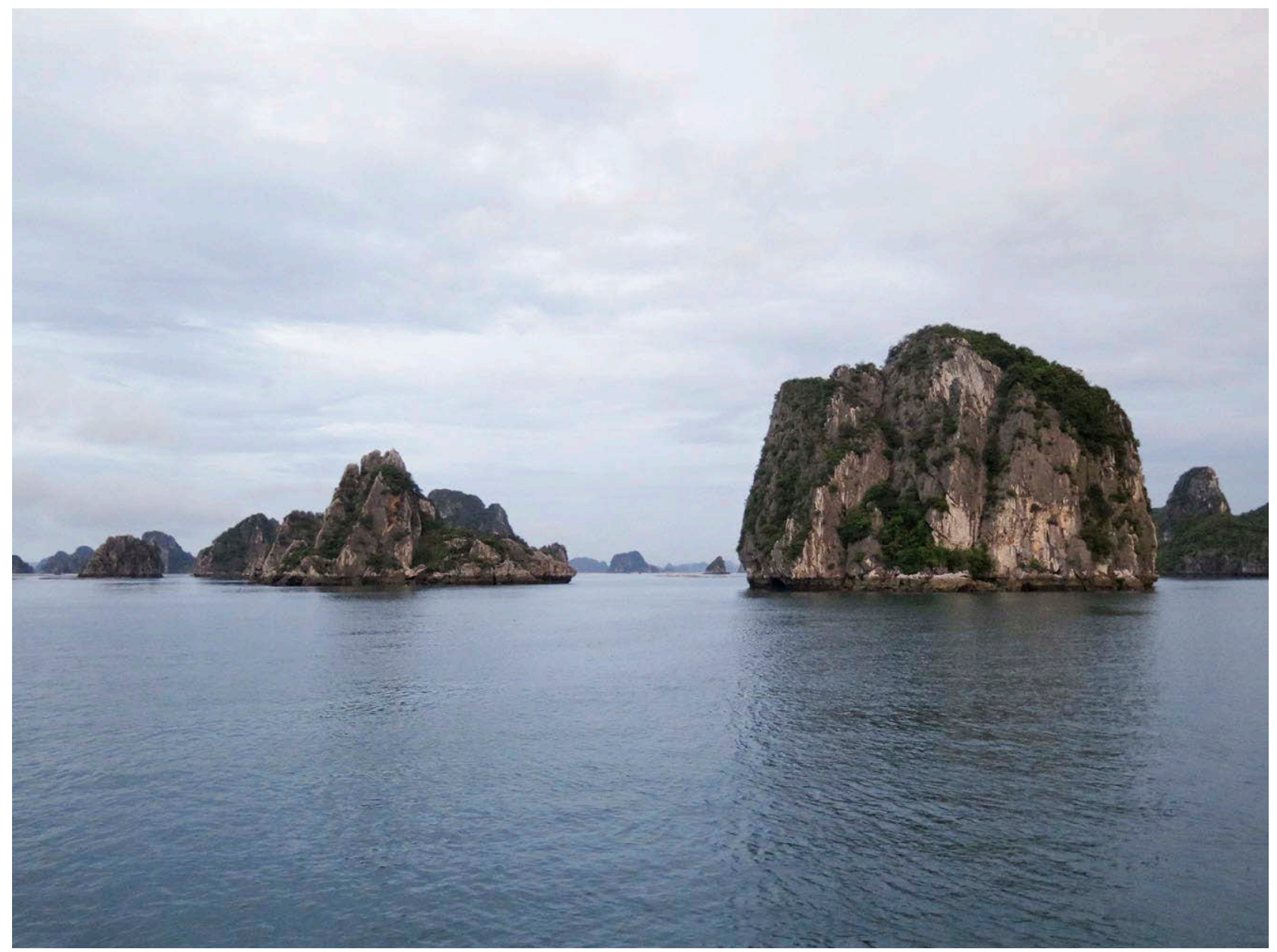

Figure 2. Ha Long Bay in northern Vietnam is a site of great beauty. A select number of pearl farms operate among the limestone casts. Photo by Kwanreun Lawanwong.

drilling process. This is just one example of why nucleus selection is critical to the end product.

Ideally, any shell used for the process should be as white and free of colored banding as possible. This is especially true in akoya farming, since the nacre deposition is usually thinner and the culturing time is not as long as for other Pinctada-species mollusks. Plain white beads of high quality are preferred, and these are costlier for farmers to purchase. Any brown, yellow, or gray bands or blemishes present in the bead will impact the final product's color since they will be notable, to some degree, in the thinner-nacred samples. Of course this is not such a concern with beads used in the production of Tahitian (Pinctada margaritifera) or some "golden" (Pinctada maxima) pearls where the nacre is usually thicker, especially in the latter, and the naturally occurring pigments mask the underlying beads more effectively than white nacre.

Devchand Chodhry, who manages two pearl farms in Vietnam and oversees others in Indonesia, wanted to start his own nuclei production facility to ensure a ready supply of high-quality white nuclei. Chodhry asked his associate at Witco Co. Ltd. to dedicate part of his garment factory in Hai Phong, a port city in northeastern Vietnam, to the establishment of this operation in December 2018. The shells imported from the United States (mainly Kentucky Lake in the state of Tennessee) are the Megalonaias nervosa (washboard), Fusconaia ebena (ebony), Amblema plicata (three-ridge), Quadrula fragosa (maple leaf), and species within the genus Pleurobema (pig-toe) ${ }^{1}$. These shells are sealed in bags and shipped by sea in containers owing to their gross weight (20 tons of shell per container). Prior to shipping, the most suitable material is sourced on behalf of Witco by a contact at Cam-

${ }^{1} \mathrm{~A}$ GIA field trip to source freshwater mussels and pearls for research from Tennessee in the United States provides further details on the mollusks; visit https://www.gia.edu/gia-news-research/freshwaterpearling-tennessee 

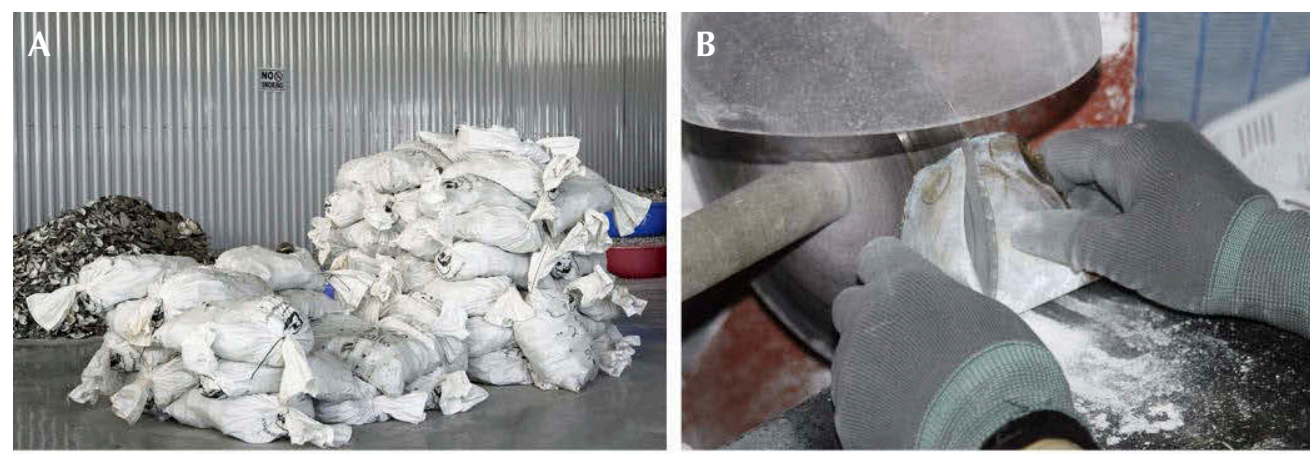

Figure 3. Photos from inside the factory showing the stages of nuclei production.
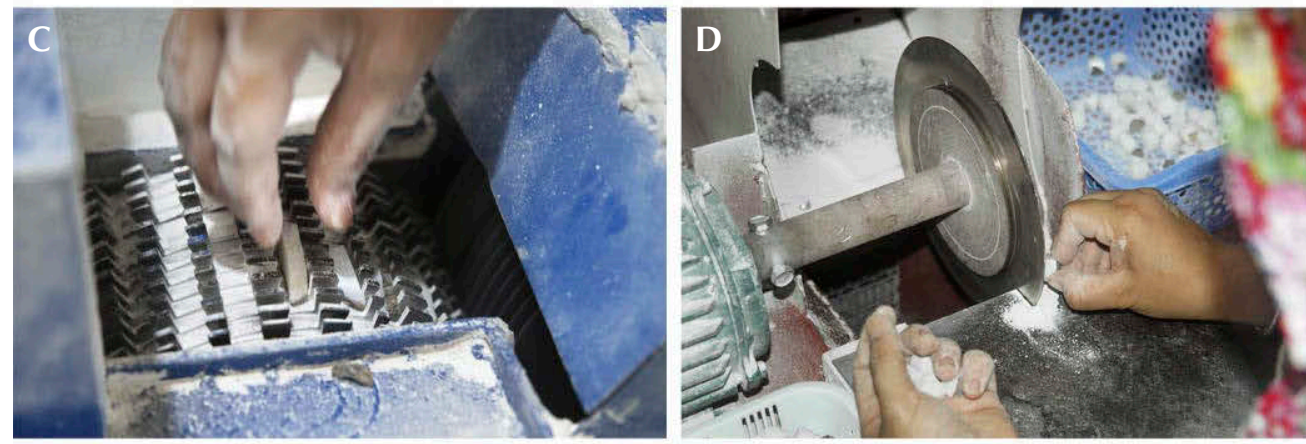

Bags of imported shell (A), sawing each valve to separate the thickest section for the larger beads (B), placing pieces of shell into a machine to cut into cuboid pieces $(C)$, grinding the corners off the larger cubes by hand (D), inserting
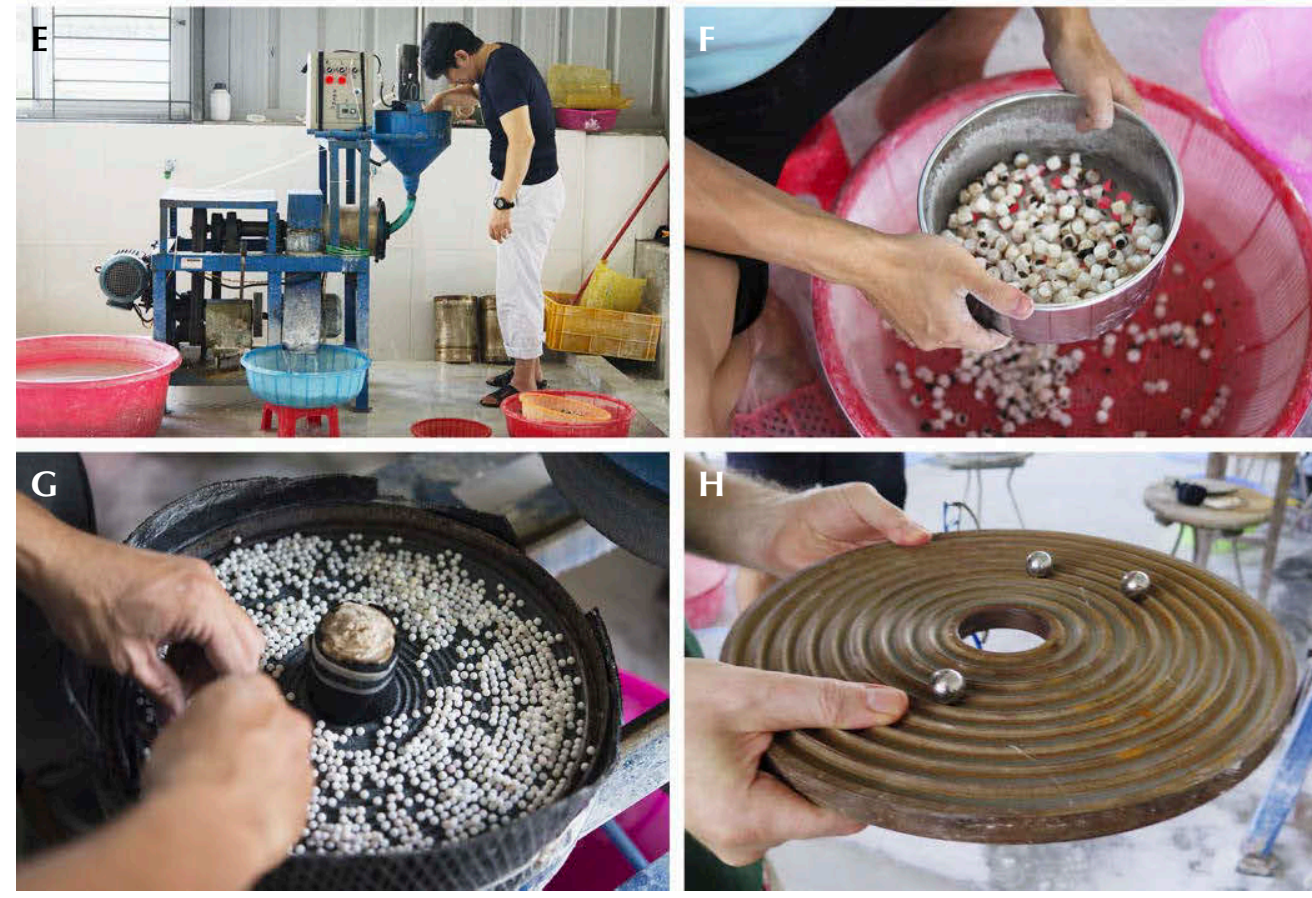
preformed nuclei into a machine that perfects the rounding process $(E)$, sieving preformed nuclei (F), checking a new group of spherical nuclei $(G)$, and the metal ball bearings used to produce the grooves in the stone discs $(H)$. Photos by Nuttapol Kitdee $(A, C, E, F, G)$, Nick Sturman $(B, D)$, and Kwanreun Lawanwong $(H)$.

den Corporation in Tennessee who has a wealth of experience handling shell and pearls in the United States. The contact has a long-standing business relationship with many of the divers in the United States and can source the quantity and quality of shell required for the Vietnamese operation. While freshwater shell is also available in India, China, and some other countries, the quality produced by the United States is more prized by the trade.
Upon receipt at the facility, the staff remove the shells from the bags and sort them into separate piles according to species (figure 3A). Processing begins with each half (valve) of the whole shell being sawn into two pieces (figure 3B). The thickest portion, from which the largest beads can be fashioned, is separated for use in the next step, which involves cutting each new portion into strips. A machine containing evenly spaced blades then cuts the strips 
into separate cube-like pieces (figure 3C). Staff use vertical blades to round the corners of the larger cubes (figure 3D) in preparation for the next step in the process, which is grinding the final spherical beads between two stone discs. The smaller cubes used for the small nuclei do not warrant such painstaking attention, so they move to another machine that automatically rounds them to the desired form (figure 3E). Next, the large and small preformed nuclei are sized by sieving (figure $3 \mathrm{~F}$ ) and then pass on to a grinding process that involves a series of stone discs of different grain sizes, from coarse to fine grain, to finalize the shaping (figure 3G). The discs arrive at the factory unscored, so another step in the process is to create the evenly spaced grooves in which the shell bead nuclei eventually sit. This is done by placing metal ball bearings onto the correctly sized ring-shaped template base. The new blank disc is lowered so that the ball bearings make contact with it, eventually creating grooves in the new disc. Water is applied throughout the process (figure $3 \mathrm{H}$ ).

The equipment in the factory is designed and tested by the experienced Witco team to improve productivity and efficiency. In this way, they can apply any improvement to the process and machinery to see if it has the desired effect.

After the grinding work is complete, the nuclei pass on to a room where a staff of predominantly women sit with Perspex-based trays on their laps and another group sits at a table with closed-sided trays. The trays are gently rocked from side to side to make the nuclei with the most perfect symmetry (roundness) roll into a basket on the floor (figure 4A). Nuclei that do not make the grade - the ones that do not roll smoothly enough-are removed by hand and returned to the previous grinding step, where their size is sacrificed for the sake of a more precise shape. Roundness is then double-checked using the closedsided trays (figure 4B), and once they pass this step, nuclei are transferred to two wooden barrels (figure 4C), where they are exposed to a weak acid treatment. The acid removes the powdery surface texture (figure 4D) and, in effect, polishes them into a final product (figure 4E). The proprietary acid bath step is very important. Too strong an acid will cause the shell to crack and etch too quickly, while too weak a solution will not effectively smooth the bead surface.

Next in the nuclei's journey comes a final check of the shape precision and color/imperfection grading so that they may be sorted into high-quality nuclei lots with matching grades for use in specific farms around the world depending on requirements (refer to earlier comment on color/imperfections and types of mollusks on farms). The shape is checked one final time using a machine (figure 4F) developed by the Chinese pearl industry that has been slightly modified and is manufactured in Vietnam. It consists of two stacked rotating glass discs with simple boundary walls that allow the beads, which gently drop from the hopper onto the outer surface of the first glass disc, to roll along. If the nuclei are perfectly spherical, they will follow the wall and drop into a basket and pass the test. If, on the other hand, there are any small flat or uneven surface areas, they will not roll smoothly and will travel away from the wall in keeping with the motion of the rotating glass. Those that fail eventually exit on the opposite side of the disc and are taken back to the grinding step. It was very evident that the speed of the glass discs was critical to this part of the process and had to be continuously monitored. The Witco team was working to make the speed more consistent or at least reduce the range of speed, for variability is sometimes needed depending on the bead size.

Color/imperfection sorting, the last step in the process, takes place in the same room as the machine with the stacked glass discs. Nuclei are examined and split into groups of varying degrees of whiteness (figure 4G). The whiter the nuclei, the better the quality and the higher the selling price. Discussions made it clear that the factory's work has just begun and they already supply nuclei to quite a few farms. Production will be increased as steps in the process allow, and different sized nuclei will continue to be produced, although all the smaller nuclei are destined for the farms operated by Orient Pearls (Bangkok) in Vietnam. The more banded or off-white nuclei are typically sent to existing clients for the production of Tahitian bead cultured pearls, where the whiteness is not as critical as in Japanese and Vietnamese akoya production. It was interesting to learn that the maple leaf mussel produces the purest white beads needed for akoya production, while the washboard mussel produces the more banded (figure $4 \mathrm{H})$ and hence less expensive nuclei that are acceptable to the Tahitian pearl farmers and farms where golden Pinctada maxima are produced.

Witco produces beads from $1.5 \mathrm{~mm}(0.49 \mathrm{Bu})^{2}$ to $6.0 \mathrm{~mm}(1.98 \mathrm{Bu})$ from the thinner areas of the shells

\footnotetext{
${ }^{2}$ "Bu" is an ancient Japanese unit of length. In metric terms, 1 bu is equivalent to $3.03 \mathrm{~mm}$.
} 

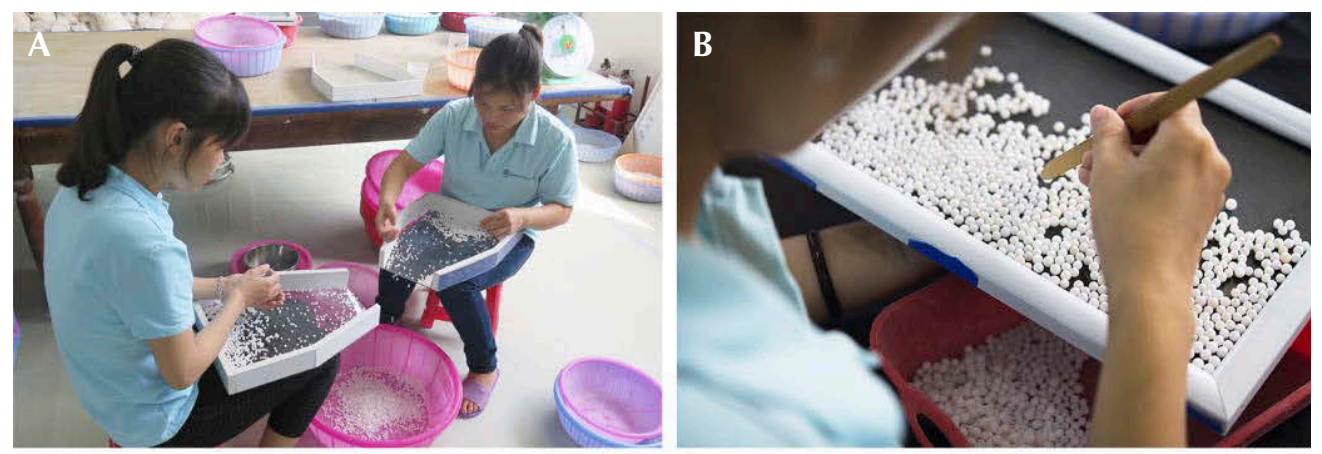

Figure 4. Photos from inside the factory show the stages of nuclei processing. Quality checks by the staff
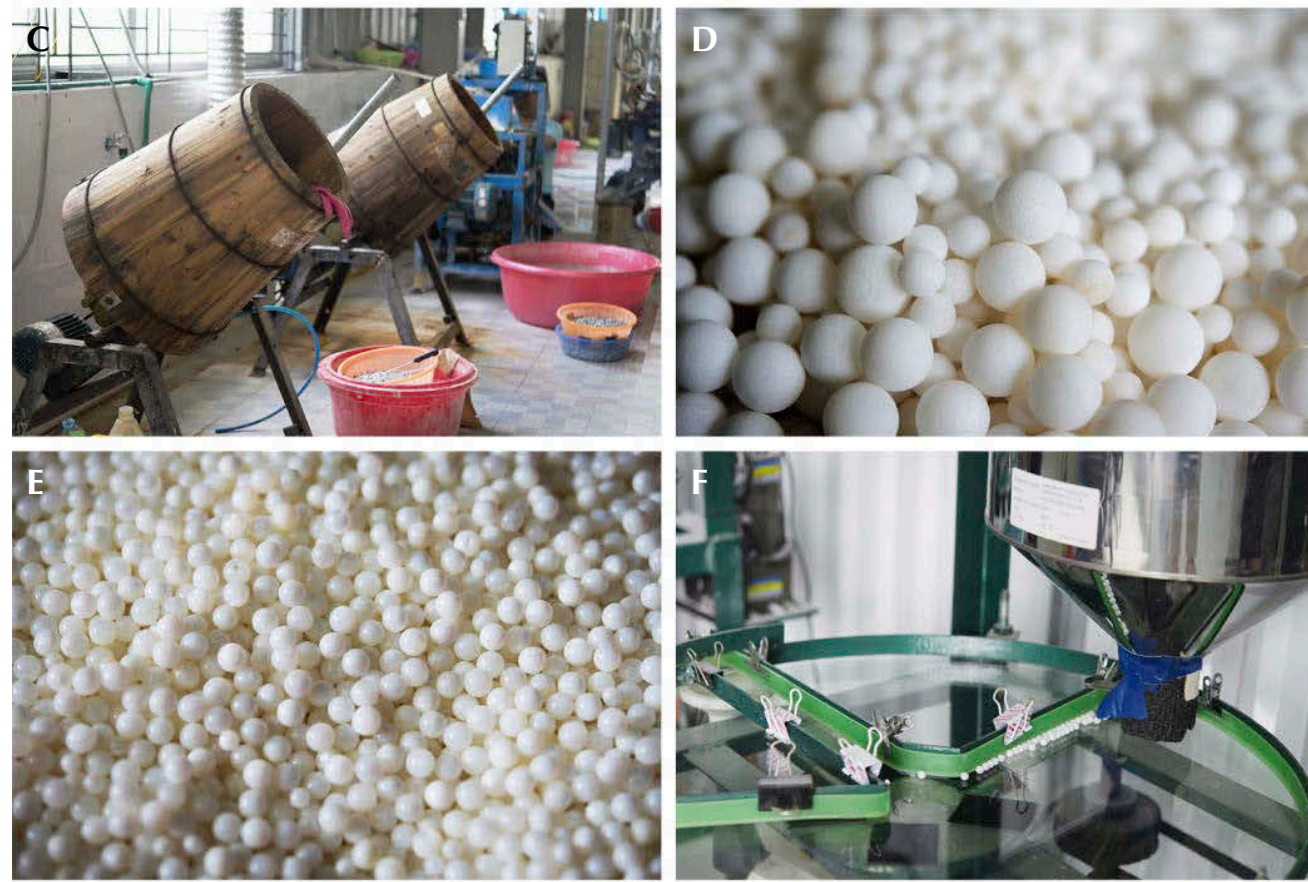

to remove any nuclei

that need further processing ( $A$ and $B$ ), wooden tumblers for removing the powder from the surface and imparting a final finish $(C)$, matte-surfaced nuclei prior to insertion into the drums (D), significantly improved surface luster after drum processing (E), the machine that checks the roundness of the fully processed nuclei (F), the final color grading/sorting step $(G)$, and a selection of washboard mussel nuclei showing clear yellow banding $(H)$.
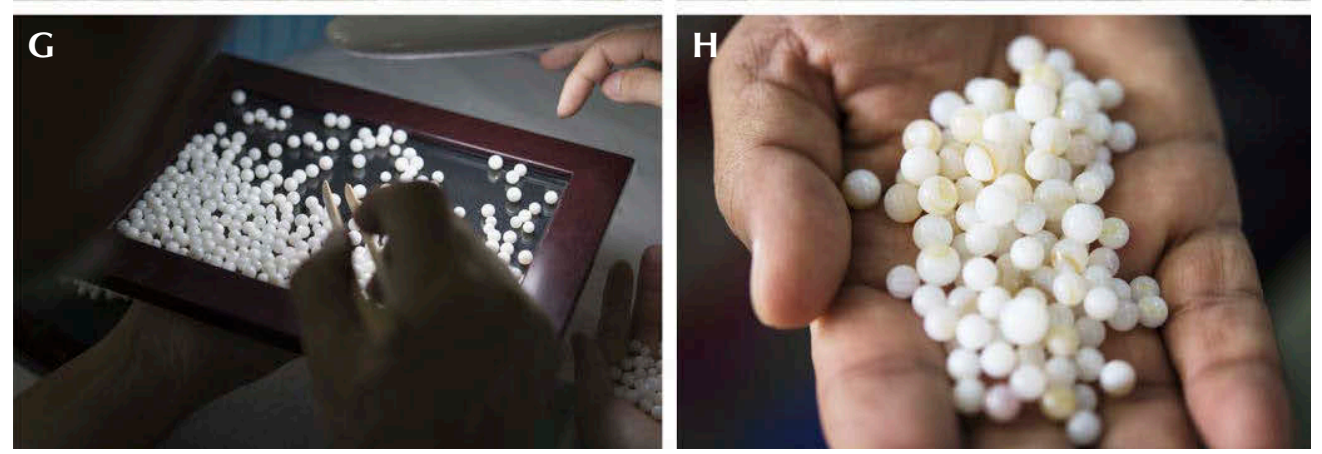
Photos by Nuttapol Kitdee (A, C, E), Nick Sturman $(B, D)$, and Kwanreun Lawanwong $(F)$.

and from $5.0 \mathrm{~mm}(1.65 \mathrm{Bu})$ to $12.0 \mathrm{~mm}(3.96 \mathrm{Bu})$ from the thicker areas of the shells. The production of very small nuclei is unique to Witco. Orient Pearls (Bangkok) Ltd. uses the production for its own farms in Vietnam to create a niche market for smaller bead cultured pearls of various attractive colors, as will be seen later when the Nha Trang farm visit is covered.

By the end of the visit to the factory, it was apparent that the roundest shape and whitest color were the paramount objectives in nuclei production. Obtaining these two goals, however, requires considerable experience, trial and error, investment, and adaptability. It was also very surprising to learn that only $3.5-4 \%$ of the imported shell leaves the factory as nuclei. The target is to produce $5 \%$ or more, but that still means that much of the original shell is not suitable for nuclei or is wasted, further underscoring the challenges of nuclei production. 


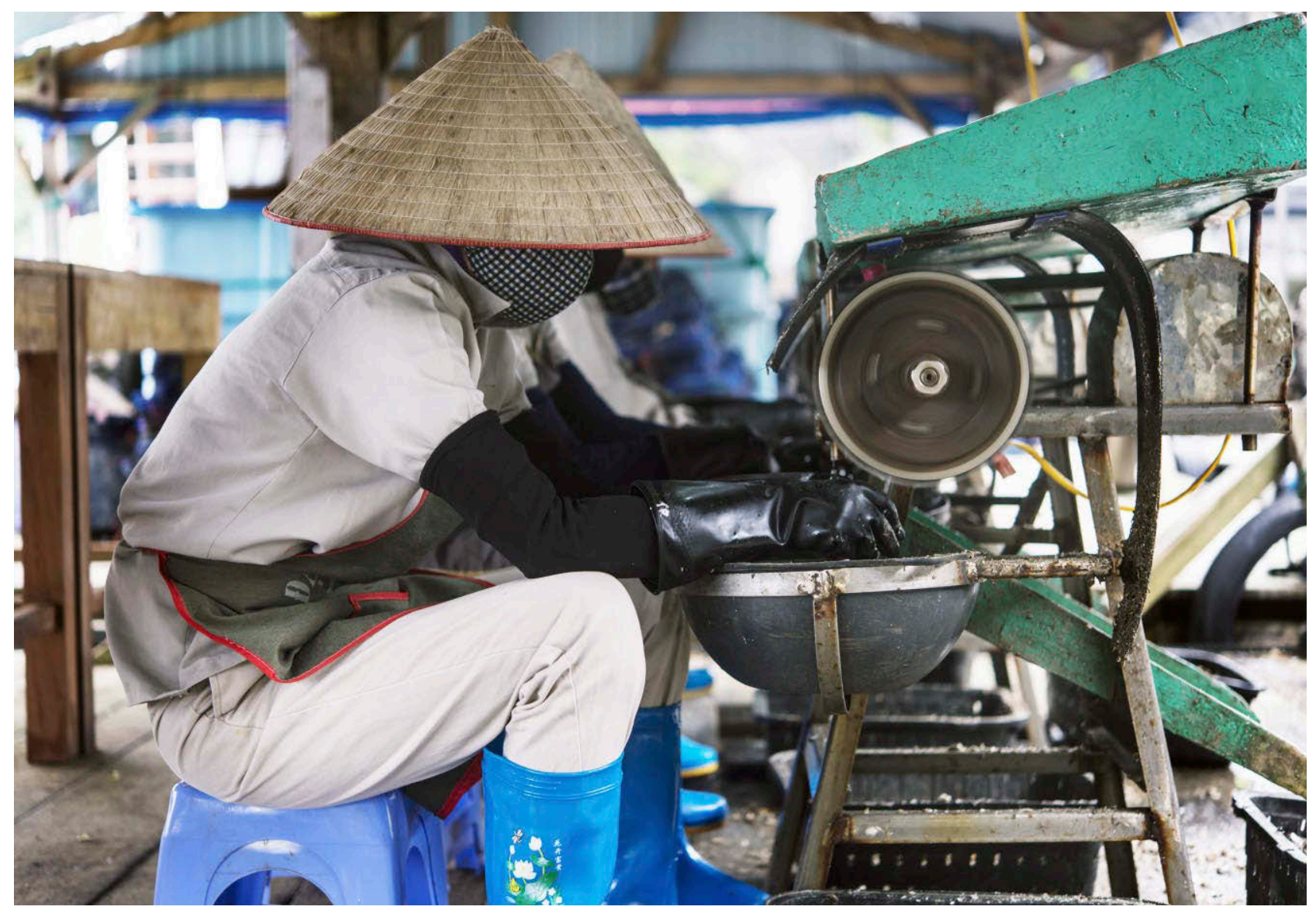

Figure 5. A POL staff member working on a series of wheel grinders to knock off surface growth from each shell. Photo by Nuttapol Kitdee.

\section{PEARL FARMING IN HA LONG BAY}

Vietnam's long coastline extends from Hai Hoa in the north to Dat Mui in the south. There are also many islands along this coastline, the most famous of which are located in Hạ Long Bay, where Pearl Orient Limited (POL) has a farm. Located a short boat trip from Dong Xa, the island $\left(21^{\circ} 03^{\prime} 12.5^{\prime \prime} \mathrm{N}, 107^{\circ} 28^{\prime} 09.3^{\prime \prime} \mathrm{E}\right)$ is perfectly positioned: close enough to the mainland for vital supplies, yet far enough away from any significant activity, such as shipping or tourism-related matters, to be of any concern to the production of pearls in a suitably clean environment.

Because the island is uninhabitable, the staff stay on the mainland. POL operates a shuttle service early each morning prior to sunrise and a return service in the late afternoon. Only six to seven staff stay on the island each night to guard the premises. When morning arrives and the guards head home to catch up on sleep, the employees brought by boat are left to work on the mollusks awaiting them.

The farm employs about 140 people. The staff are split into various groups with specific duties to perform. These responsibilities range from cleaning the shells, preparing the shells for operation, cutting and preparing the mantle tissue from the donor mollusks, and nucleating/seeding the host mollusks to collateral tasks such as preparing meals for the staff.

The day starts with selecting shells for the donor mantle tissue (saibo) and the hosts in which the nuclei are inserted. The chosen shells are removed from the holding area for preparation. These are stock previously transferred from the nursery area (see later in the report). The shells are cleaned in a number of ways, using hand tools for scraping and wheel grinders (figure 5) that remove most of the associated organic growth. A two-minute soak in a saturated salt bath helps to kill any parasites living on the shells. Once these steps are complete, the shells are selected and separated by size into groups of 80150 , which are then placed in black plastic containers and returned to the sea to be monitored. Those that are ready for the operation are also placed in an ozone tank for around eight hours to remove any 
bacteria and byssus ${ }^{3}$ prior to transfer to the nucleation room.

When the mantle donor shells are ready, the staff quickly and expertly cut the desired section of mantle from each shell and trim away the outer fringe from the inner whiter area. They are mindful to remove any colored areas from the final small pieces of mantle that will be used in the nucleating process, since these have been shown to have detrimental effects (discoloration, off-shape pearls, and surface blemishes) on the final product. The pieces of mantle destined for the host shells are quickly coated in antiseptic to ensure they remain as healthy as possible until insertion in the mollusks.

The next step is the nucleating or seeding itself. With the akoya shells, only one operation is ever performed, unlike in Pinctada maxima where two or more operations may take place depending on certain scenarios. This is because the shells are smaller and have a shorter life span of only 4-6 years, whereas the $P$. maxima can live for 20-30 years. On POL's farm, each akoya mollusk is nucleated with between one and four shell nuclei, depending on the size of the nucleus. If the smaller sizes below 3.03 $\mathrm{mm}(1 \mathrm{Bu})$ are used, three or four beads are inserted into the host. For nuclei measuring 3.6-4.8 mm (1.2$1.6 \mathrm{Bu}$ ), two shell bead nuclei are inserted, while larger beads of $5.7 \mathrm{~mm}(1.9 \mathrm{Bu})$ or above are inserted singly into each host. The skill of the operators is critical in performing this work quickly and effectively, for the quality of the end product depends on their talents. It was notable that all the employees performing this step were women owing to the belief that they are able to perform this delicate operation with better results.

When one looks at an unopened Pinctada fucata shell, one side shows a concave surface near the lip area. This is considered the right-hand side. It is in the gonad protected within this area of the pocket that nuclei are implanted during the seeding operation. The actual placement of the nuclei within the gonad is also of critical importance. With small beads, the placement of the two, three, or four nuclei together with the corresponding individual pieces of mantle become even more critical. Incorrect positioning may result in twin pearls, low-quality pearls, or no pearls at all.

${ }^{3}$ The mass of strong threads ("sea silk") secreted by some mollusks at the hinge end by which they are able to attach themselves to rocks and other stable surfaces.
After the operations are complete, the mollusks are placed into suitably sized nets with strips of plastic tubing that prevent the mollusks from moving around freely. The nets are subsequently taken to a holding area to be monitored for approximately two to three weeks, or until the piece of mantle forms a pearl sac around the shell bead. Then they are transported to the longlines in the waters within the farm limits, where nature takes its course and layers of nacre are deposited in the pearl sac to form pearls before their eventual harvest. At the time of the visit, the farm's stock consisted of approximately one million shells: 100,000 were seeded with one nucleus, 450,000 with two nuclei, and 450,000 with four nuclei.

Although we did not visit during a designated harvest period, POL was kind enough to remove some akoya from their nets and show us the results. This quality check is carried out every month to monitor the health and progress of the mollusks from the various operation dates. Shells with one, two, and four nuclei were chosen, and in almost all cases the number of pearls matched the number of nuclei inserted. In a few examples, however, no pearl was found-not an uncommon situation - and in some of the dual or quadruple operations, an uncoated nucleus was removed. This clearly shows that the process does not always work and that nature makes its own decisions.

After the mollusks have been in the water for a few months, their health is monitored, as we witnessed on the day we visited, by pulling up the nets and making a quick inspection of a random sample. Healthy mollusks tend to show "fingers" on the lip fringe that are intact and protruding, while those that are not so healthy show the opposite. Sadly, dead shells are lifeless and already open. This is something no pearl farmer wishes to see, but it is an inevitable part of the farming process, and the mortality rates are monitored closely. Detailed record keeping of every stage of the seeding process, post-operative care, and eventual placement of each group of operated mollusk allows the staff to check the shells' progress prior to the scheduled harvest date.

As with all pearl farms, the mollusks also need to undergo regular cleaning. The farm uses two specialized cleaning boats, each mounted with a conveyortype cleaning unit. The fouled nets and shells are pulled up and fed into the unit, which uses high-pressure water jets. Afterward, the nets with their shells are returned to the water, and the remnants of the cleaning process may be seen as a cream to beige stain spreading behind the vessel as it continues its way down each longline, cleaning every net sus- 


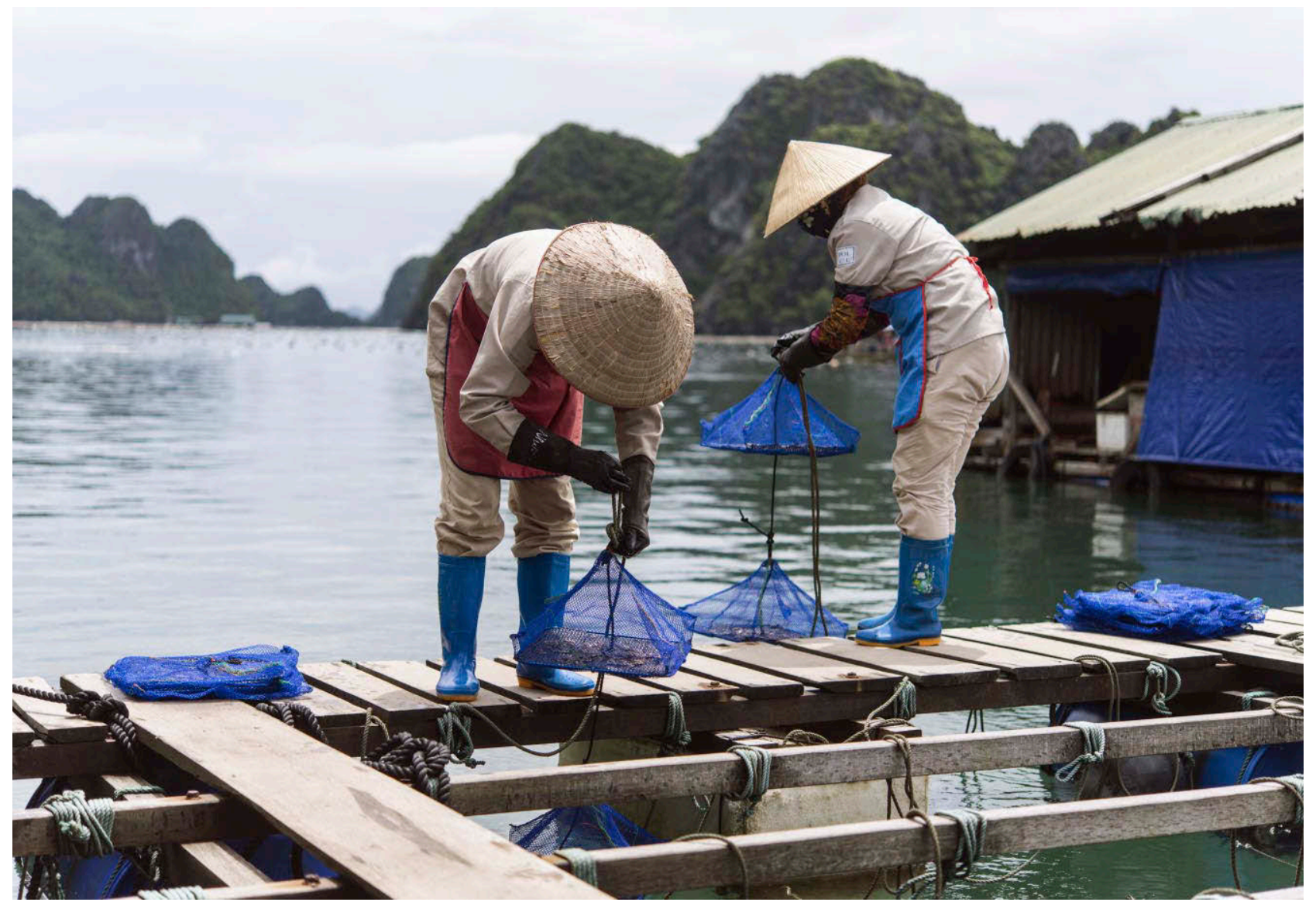

Figure 6. Staff at the nursery placing nets containing Pinctada radiata mollusks into the waters of Ha Long Bay. Photo by Nuttapol Kitdee.

pended. This process is laborious but vital to the whole operation.

On the way back to the harbor, we detoured to another area of $\mathrm{Ha}$ Long Bay $\left(21^{\circ} 01^{\prime} 37.5^{\prime \prime} \mathrm{N}\right.$, $107^{\circ} 27^{\prime} 35.6^{\prime \prime} \mathrm{E}$ ), a short distance from the main farm, where the spat are cared for. In this area, a separate team checks the spat received from the Nha Trang farm where Pearls Vietnam Limited (PVL) has its hatchery. Sizes are checked using a sieve before transfer to triangular blue nets (figure 6), which are suspended under wooden rafts for monitoring. Only when they reach the right age of around one year are they moved to the main farm for the team there to start working on them in the way described earlier.

It was very interesting to note that POL is experimenting with Pinctada radiata mollusks sourced from the Middle East but obtained via Japan and subsequently sent to Vietnam. This group has strong links with Japan and this was clearly visible in all steps of the operation. The use of this mollusk seems a good choice, as it is more suited to warmer waters than Pinctada fucata martensii, and its faster nacre deposition means that the nacre coverage is ultimately thicker. The possibility of producing hybrids is also being considered. The future certainly looks promising, and we may start to see a greater variety of Vietnamese pearl products in the market.

\section{PEARL FARMING IN NHA TRANG}

The PVL pearl farm is located in southern Vietnam $\left(12^{\circ} 40^{\prime} 02.4^{\prime \prime} \mathrm{N}, 109^{\circ} 12^{\prime} 36.8^{\prime \prime} \mathrm{E}\right)$ around one hour's drive from the city of Nha Trang, a popular tourist destination. It is far away from the main sources of pollution encountered from a concentrated area of humanity. Like the POL farm in Hạ Long Bay, it focuses on the production of akoya pearls from the Pinctada fucata martensii mollusk and follows the steps detailed previously for the northern farm. However, there are differences between the two. PVL produces the brood shell stock in its own hatchery for both farms, and the ratio of colored pearls to white and cream ones is higher in the northern farm since a greater percentage of silver, gray, and blue pearls are produced there. 
However, the obvious difference between the two farms is the plentiful fresh water supply on this mainland farm, presumably part of the reason it is used as the hatchery location as well. Although the mollusks live and breed in the marine environment, fresh water plays a crucial role in the cleanliness needed to limit infection in the breeding and grafting steps. The use of fresh water is therefore more prominent in the hatchery and pre-operation mollusk preparation than on the northern farm. Some interesting facts about the care and pre-operation preparation of the Pinctada fucata martensii on the PVL and POL farms (noting that there are differences with other mollusks and farms) include:

- When moved from the hatchery to the sea, the mollusks need to be cleaned once a month.

- The age at which they are seeded ranges between 9 and 12 months. On the day of our visit, the shells being operated on were 10 months old.
- Prior to the grafting process, they are placed in a freshwater tank (figure 7) for two hours to kill the saltwater parasites and other guests living on or in the surface layers of the shells. The mollusks can tolerate the fresh water by closing tightly, while the other organisms cannot survive this long in fresh water.

- The shells are quickly dipped into a strong salt bath to kill any parasites or bacteria. Salt is used in the same way during the cleaning process. They are submerged for two minutes.

- The ozone process carried out in one tank helps remove the "legs" or byssus.

- The mollusks are immersed in an anesthetic bath to relax them prior to seeding. The time spent in the bath varies very slightly between the two farms and also depends on the size of the shells. It usually lasts around 10 minutes on the POL farm and around 14 minutes on the

Figure 7. The saltwater mollusks are placed in freshwater tanks for around two hours to kill any parasites or organic growth on or within the outer surface layers. The PVL farm manager, Mr. Kado (pictured), is the driving force behind the farm's success. Photo by Nuttapol Kitdee.

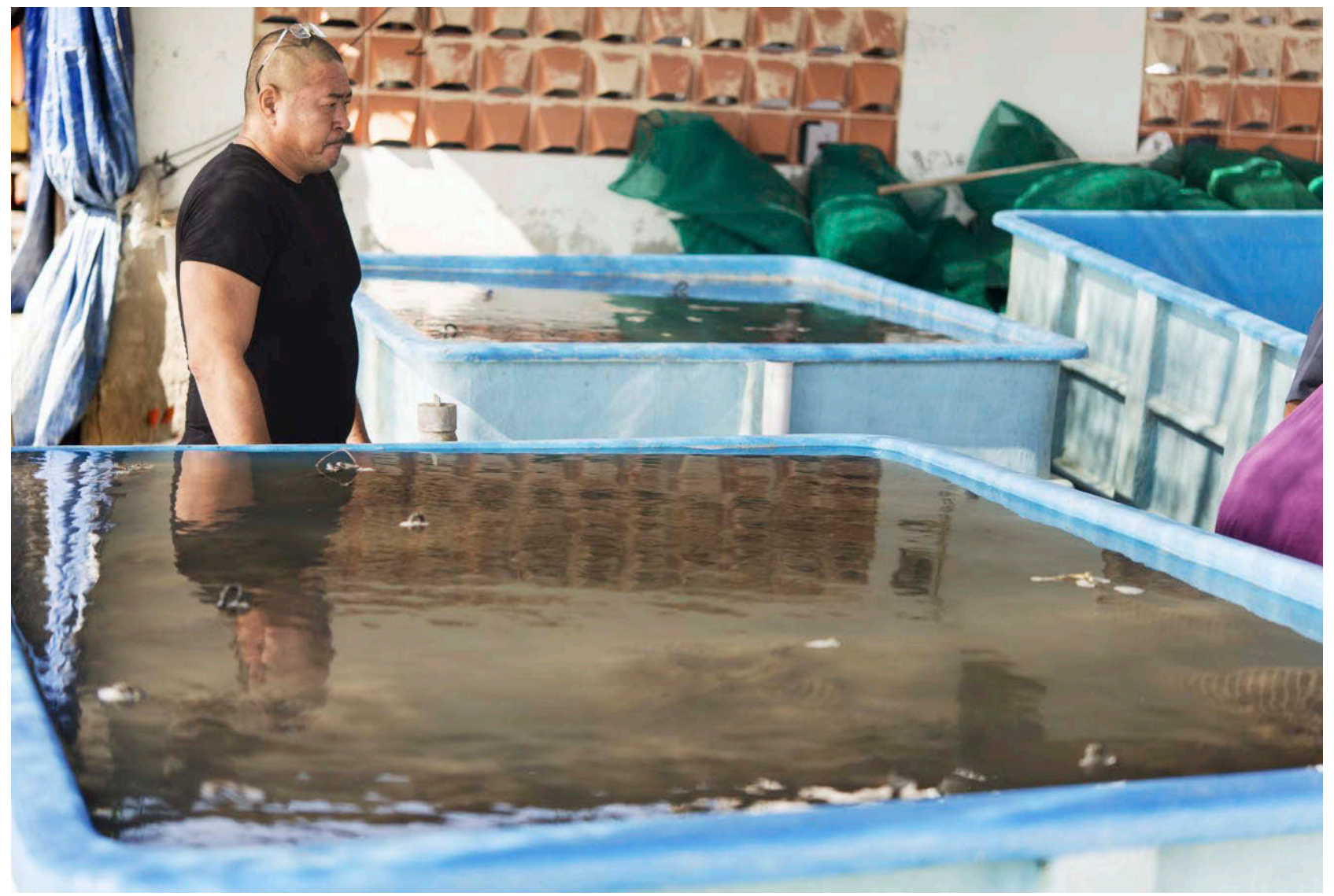


PVL farm. The concentration of the anesthetic also varies from $47 \%$ on the POL farm to $46 \%$ on the PVL farm.

- The fully anesthetized mollusks are easy to spot, as their shells are open. The ones that are not fully open need to be pegged in preparation for the next step. However, even the fully relaxed and open mollusks eventually need to be pegged before the anesthetic begins to wear off.

- After the operation, the mollusks are suspended in a tank. Numbers on the variously colored tags identify the technician who carried out the seeding. This information is valuable, as not all technicians share the same skill level; some may produce a pearl with better shape or a higher percentage of a specific shape.

- The operational head technician, who is from Japan, stated that from his experience, the pearl sac takes five to seven days to form post-operation.

- The mantle used was from donor shells that were a month younger than the host.

- Before being placed in the sea post-operation, the shells are inserted into pockets in nets, and then each one is further inserted into two fine green mesh covers for protection. After one week, the first green net is removed, and a week after that the last green net is removed. This ensures that the pearl sac forms and the newly formed byssus stick with other shells and the host net. The formation of the byssus limits the shells' movement within the nets.

Most hatcheries are set up in a similar way (Cartier at al., 2012). They depend on producing larvae from the eggs and sperm of suitable parents and then closely monitoring and feeding the larvae and spat as they develop from the former to the latter. The PVL farm is no different in this respect, but the use of fresh water during some steps of the process seems to differentiate the hatchery and farm from their peers.

In the hatchery, we noted the typical darkened conditions in the area where the tanks holding the larvae and spat are situated, though more lighting is provided when staff or visitors are in the area. Various tools such as nets with varying mesh sizes for different stages of larvae to spat formation were on hand, and the tanks were oxygenated to ensure the survival of the spat. The spat generally start to attach themselves to structures after 20 days (Otter et al.,
2017). This is when they transform from the larval stage, where they are free-swimming organisms, to spat form. On the day of our visit, the spat were 25 days old. Although small, they could clearly be seen attached to the black plastic screens suspended in the tanks. To keep the hatchery free of possible contamination, staff and guests must wash their hands and feet with fresh water and detergent before entry. Staff also wear hairnets and masks to prevent potential contamination of the tanks. In this way, the larvae and spat can reach a suitable age (usually 35-45 days), at which point they are taken out to the sea just a few meters away to be suspended from the rafts and longlines in the baskets and nets.

Before they are able to reach the sea, the spat and their larval stage have to be fed. The rest of the hatchery rooms are dedicated to producing the different phytoplankton required for three different age groups. The larvae are fed Pavlova lutheri and Isochrysis galbana from birth, and after five days Chaetoceres gracilis is added for further nutrition. Meticulous work goes into ensuring that the right nutrients are produced in the numerous glass vessels lining the shelves of the air-conditioned rooms. The stock is kept under optimum conditions so there is always a supply of food for the larvae or spat at any given time.

When they eventually make it to the sea, they are monitored to ensure the best possible conditions in which to continue developing. Mortality rates must be kept at a minimum for farmers to have any chance of producing enough pearls to turn a profit. When other overhead costs such as staffing and general operation are taken into account, this becomes even more challenging. Every step of the process is important. Weather is an additional factor, one that pearl farms have absolutely no control over. Extreme weather can wipe out farms and destroy the longlines and mollusks in some areas of the world (the Philippines being a prime example), yet this is less of a factor in Vietnam. Sea conditions also play a role in the way the farm is operated. The water is shallower and the seabed muddier in the Nha Trang farm than in the Hạ Long Bay farm, which results in more frequent cleaning as the baskets and nets quickly become clogged with sediment. The fouling in Ha Long Bay is linked more to the marine life that attaches itself to the shells and structures in which they are housed. Thus, as in the northern farm, cleaning vessels are used to periodically move along the longlines and free the mollusks of any unwanted sediment or growth. PVL uses four cleaning vessels, one on floats, to do this work on a slightly more frequent basis. 


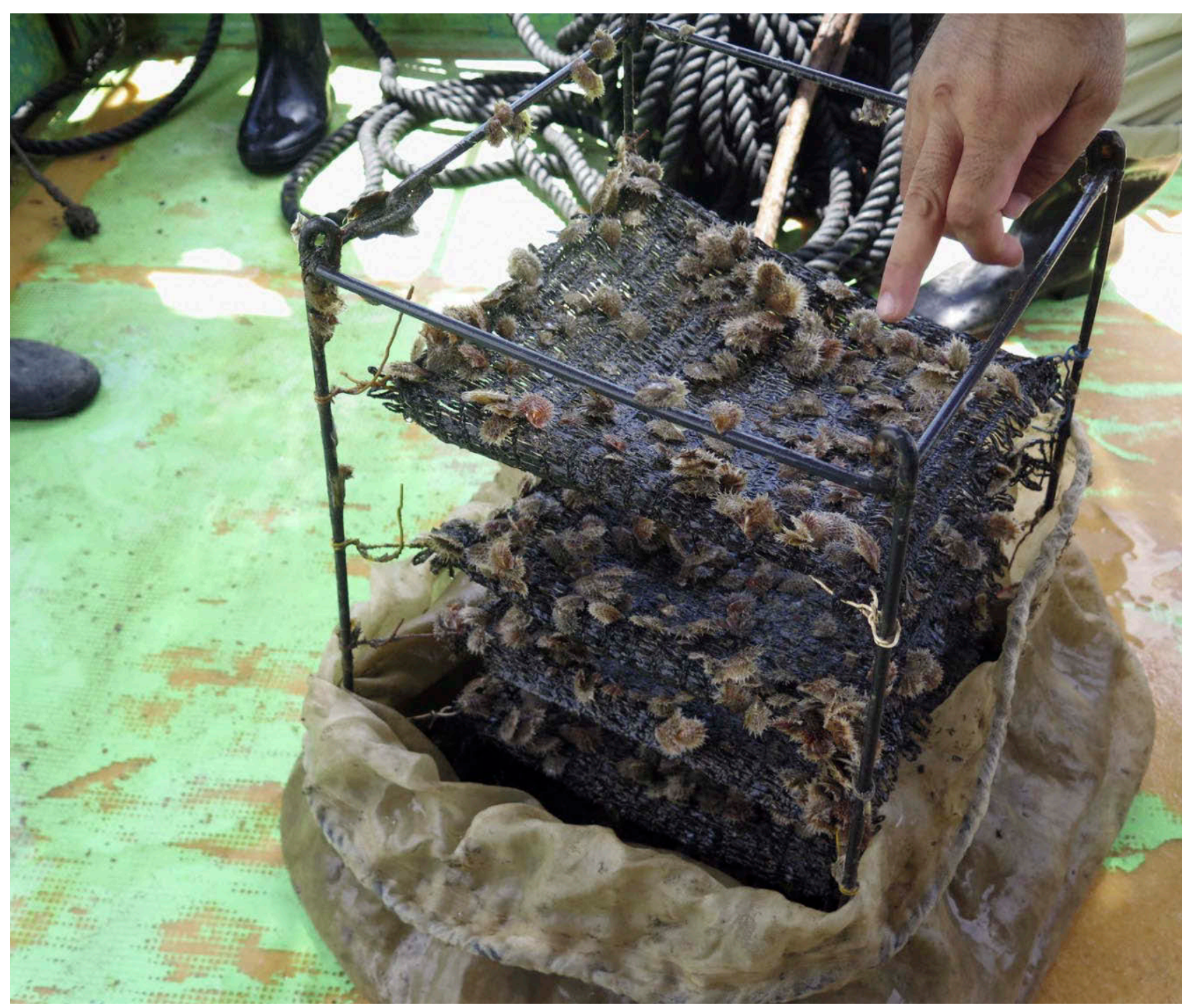

Figure 8. Pinctada radiata spat upon removal from the sea during a quick check of their health. The long and prominent "fingers" extending from the shells' lips indicated they were in good health, and no obvious mortality cases were evident. Photo by Kwanreun Lawanwong.

During our brief visit, we took a boat trip out to the longlines to see the mollusks and nets used at the various stages of their growth cycle. Although the majority of the mollusks were Pinctada fucata martensii, we were shown some Pinctada radiata (figure 8) that had recently arrived from the northern farm via Japan and been sourced from the Middle East. They were being cared for in order to see whether they could be reproduced in the hatchery at a later date once suitable parent stock was identified. The mollusks were enclosed in a fine hemp bag that covered a three-tiered structure on which the shells were sitting. They all looked healthy, and the plan was to introduce them, as previously noted in the section on the northern farm, to see whether they would produce better pearls with thicker nacre given that they are a species that better tolerates warmer waters. Other stages of the growth cycle where mollusks were kept in different nets were also observed, as were some mollusks that had already been operated upon on different dates. Some contained a single bead, while other mollusks from different operation dates grouped in other areas of the farm's waters contained two or four nuclei.

Back on dry land, we witnessed the opening of some shells to see the results of earlier operations. Ten mollusks operated on in December 2018 were 


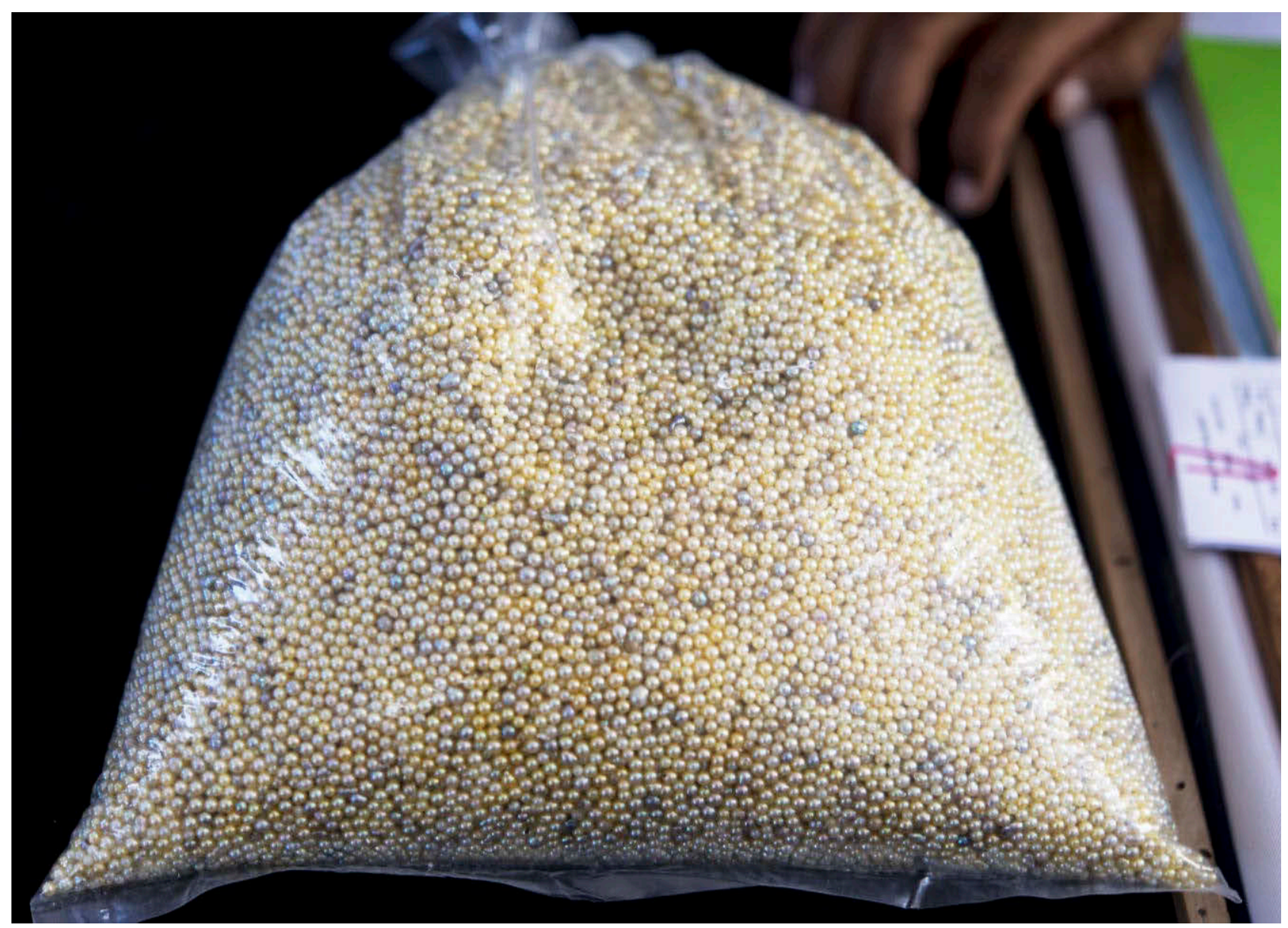

Figure 9. One of the many bags of pearls kept in the farm's office before being sent to Bangkok. The range of colors is very evident, and the white to yellow pearls are the most desirable range for Orient Pearls' end products. There is also a healthy demand for the silver, gray, and blue colors. Photo by Nuttapol Kitdee.

checked first, and the outcome of the eight-month formation period was the harvesting of ten pearls ranging from white to light yellow. The nacre condition looked good during the duration of growth permitted prior to their extraction. Ten mollusks from three other seeding operations were also opened in our presence, and we witnessed the removal of pearls from a two-nuclei operation and pearls from a couple of four-nuclei operations.

The final part of the day was spent in the office inspecting the bags of production (figure 9) from the safe and watching the sorting process. The quantity of pearls was impressive, and this was because the northern farm's production is sent to the southern pearl farm post-harvest for sorting. Here the staff check for the usual criteria-size, shape, color, luster, and surface imperfections-before grouping them into lots for further inspection during Chodhry's regular visits. After his inspection, they are shipped to Orient Pearls (Bangkok) for further sorting and pro- cessing before ultimately being used in all types of jewelry for sale and distribution globally. Orient Pearls (Bangkok) is particularly proud of its range of uniquely small (1.5 to $5.0 \mathrm{~mm}$ ) akoya cultured pearls ranging in color from white to yellow, as well as the greater quantities of similarly sized silver to light gray akoya with a bluish appearance produced at the northern farm. It is not very clear why there should be such a difference in colors when the mantle choices from the donors are similar, as are the hosts, and the techniques employed through the husbandry and farming processes are consistent. A visiting manager from the southern farm on the day of our visit suggested that the bluish color of the pearls results from the effects of bacteria in the northern farm's waters. Staff noted a greater variety of marine life and parasites in the waters of Ha Long Bay than those of the southern farm. This is still a subject of discussion and could be an interesting case study going forward, since it is outside the scope of this field report. 


\section{SUMMARY}

Vietnam is clearly a cultured pearl producer of note and, to a lesser degree, a source of shell bead nuclei. While there are a number of pearl farms in the north and a few in the south producing mainly akoya pearls, there is only one shell nucleus factory the authors are aware of today. The detail and commitment required to turn shell valves into high-quality bead nuclei on a consistent basis, and for the same nuclei to eventually end up in the center of bead cultured pearls, was evident from our time in Vietnam. All pearl farms operate along similar lines (Cartier et al., 2012; Sturman et al., 2016), yet it is also fair to say that they all have their own traits and quirks that differentiate them from one another. Whether it is the way the parents and spat are handled by hatcheries (which are not available at all farms), the subtle dif- ferences in the methods used to prepare the mollusks pre-operation, or the techniques employed in the grafting process itself, there is always something to learn from visiting a pearl farm.

The chance to witness this process close-up can be appreciated by anyone given such an educational and enjoyable opportunity. This report hopefully educates those unable to visit pearl-related sites in person, provides a valuable reference to those who have visited other farms, and proves how much dedication (financial and personal) is needed to run such ventures on a commercial basis. To this end, Chodhry noted that after 19 years, the Hạ Long Bay farm was only just starting to be cash-flow positive, illustrating this point. Pearl farming in particular is hard work, but all the farmers met by the lead author said, without exception, that the effort and expense are worth the results.
ABOUT THE AUTHORS

Mr. Sturman was formerly senior manager of pearl identification, Ms. Lawanwong is an analytical technician, and Mr. Kitdee is a digital imaging technician, at GIA in Bangkok. Mr. Chodhry is chairman of Orient Pearls (Bangkok) Ltd.

\section{ACKNOWLEDGMENTS}

The hospitality shown to the GIA team during the visits to the nucleus factory, the Ha Long Bay farm, and the Nha Trang farm cannot be underestimated. While all three locations had to operate as usual, our presence, while not a major factor, created some impact on the daily workflow.

\section{REFERENCES}

Cartier L.E., Krzemnicki M.S., Ito M. (2012) Cultured pearl farming and production in the Federated States of Micronesia, $G \uplus G$, Vol. 48, No. 2, pp. 108-122 http://dx.doi.org/10.5741/GEMS.48.2.108

Heebner J. (2015) Shell game. Jewelers Circular Keystone. Vol. 166, No. 9, pp. 100-103.

Otter L.M., Agbaje O.B.A., Huong L.T.-T., Häger T., Jacob D.E. (2017) Akoya cultured pearl farming in eastern Australia. $G e G$, Vol. 53, No. 4, pp. 423-437, http://dx.doi.org/10.5741/GEMS.53.4.423

Shor R. (2007) From single source to global free market: The transformation of the cultured pearl industry. $G \uplus G$, Vol. 43, No. 3, pp. 200-226, http://dx.doi.org/10.5741/GEMS.43.3.200

Sturman N., Bergman J., Poli J., Homkrajae A., Manustrong A. Somsa-ard N. (2016) Bead-cultured and non-bead-cultured pearls from Lombok, Indonesia. Gせ G, Vol. 52, No. 3, pp. 288297, http://dx.doi.org/10.5741/GEMS.52.3.288

Strack E. (2006) Pearls. Rühle-Diebener-Verlag GmbH, Stuttgart, Germany, $708 \mathrm{pp}$.

Taylor J., Strack E. (2008) Pearl production. In P.C. Southgate and J.S. Lucas, Eds., The Pearl Oyster. Elsevier, Oxford, UK, pp. 273-302. 